\title{
OXIDAÇÃO DO MINÉRIO SULFETADO E FORMAÇÃO DE GOSSANS AURÍFEROS NA REGIÃO DE SÃO BARTOLOMEU (GO)
}

\author{
NELSON MARINHO DE OLIVEIRA * \& SÔNIA MARIA BARROS DE OLIVEIRA**
}

\begin{abstract}
OXIDATION OF SULPHIDE ORE AND FORMATION OF GOLD-BEARING GOSSAN IN THE SÃO BARTOLOMEU REGION (GO) The gossans of São Bartolomeu region formed in situ by the oxidation of sulfide bodies containing pyrite, galena, chalcopyrite and sphalerite, and small amounts of gold and silver. Texture, chemical and mineralogical composition were determined. Goethite is the most abundant mineral in gossans, but iron is also present as hematite and amorphous compounds. Typical boxwork textures derived from pyrite were observed. The geochemical signature of the gossans is particularly high in $\mathrm{Pb}$ and $\mathrm{Zn}$, moderate in $\mathrm{Cu}$, with anomalous contents in $\mathrm{Au}$ and $\mathrm{Ag}$. The chalcophile elements have co-precipitated with Fe, resulting in the high contents determined by SEM-EDS in the Fe oxy-hydroxides. Gold occurs as irregularly distributed sub-millimetric particles in the ferruginous plasma. The mean content of Au in gossans is 2 ppm, attaining locally up to $30 \mathrm{ppm}$.

Keywords: Gossan, Gold, Chalcophile metals, São Bartolomeu (Goiás State)

RESUMO Os gossans da região de São Bartolomeu formaram-se in situ a partir da oxidação de corpos sulfetados que continham pirita, galena, calcopirita e esfalerita, com pequenas quantidades de ouro e prata. Foram determinadas textura, composição química e mineralógica dos gossans. A goethita é o mineral mais abundante, mas o ferro também está presente como hematita e em compostos amorfos. Foram observadas texturas boxwork típicas derivadas da alteração da pirita. A assinatura geoquímica dos gossans é particularmente alta em $\mathrm{Pb}$ e $\mathrm{Zn}$, moderada em $\mathrm{Cu}$, com teores anômalos de $\mathrm{Au}$ e Ag. Os elementos calcófilos precipitaram com o ferro, resultando nos altos teores determinados por MEV-EDS nos óxi-hidróxidos de ferro. O ouro ocorre com partículas sub-milimétricas irregularmente distribuídas no plasma ferruginoso. O teor médio de Au nos gossans é $2 \mathrm{ppm}$, podendo atingir localizadamente $30 \mathrm{ppm}$.

Palavras-chave: Gossan, Ouro, Metais calcófilos, São Bartolomeu (GO)
\end{abstract}

INTRODUÇÃO Em vista da crescente demanda mundial e do aumento dos preços do ouro na década de 1980, a Metais de Goiás S/A - MET AGO - empreendeu prospecção regional para esse metal nas áreas de fílitos carbonosos do Grupo Canastra, próximas a Luziânia. Essas áreas já eram conhecidas desde os tempos coloniais como produtoras de ouro, que era extraído de garimpes, usando principalmente mão-de-obra escrava. A produção de ouro nesses sítios permaneceu até o final do século passado, quando decresceu o teor nos filitos, e foram descobertas novas jazidas com teores mais elevados em outras regiões do país. Ainda permanecem na área, encobertos pela vegetação, as escavações, os rejeitos, os canais d'água etc. (Hagemann 1988).

A METAGO selecionou, para iniciar os trabalhos, a região do vale do rio São Bartolomeu, que localiza-se a cerca de $50 \mathrm{~km}$ a sudeste de Luziânia e de $50 \mathrm{~km}$ ao norte de Cristalina (Fig. 1). Inicialmente foi realizada prospecção geoquímica sistemática por sedimentos de corrente, que resultou na descoberta, em 1988, de uma anomalia de $\mathrm{Au}-\mathrm{Ag}-\mathrm{Cu}-\mathrm{Pb}-\mathrm{Zn}$, denominada Alvo Cabeça Seca. Seguiram-se as etapas de reconhecimento geológico e de caracterização da anomalia (geoquímica de detalhe em solos), quando foram identificados materiais superficiais tais como gossans e fílitos portadores de vênulas de quartzo com até $18 \mathrm{ppm}$ de $\mathrm{Au}$. Com a finalidade de expor as mineralizações auríferas responsáveis pelas anomalias detectadas, foram cavadas trincheiras de onde foram retiradas 297 amostras das porções mais venuladas dos filitos e dos níveis gossânicos. Os melhores resultados para ouro estiveram relacionados aos gossans, atingindo até $30 \mathrm{ppm}$. Em vista disso, foram selecionadas as duas trincheiras mais ricas, T6 e T8, para investigação sub-superficial por sondagem a diamante. Os resultados não foram muito animadores, pois mostraram que os ore shoots sulfetados apresentavam dimensões reduzidas e baixos teores fora das zonas de oxidação (Lacerda Neto \& Matos 1990). A pesquisa mineral não prosseguiu, e a área foi abandonada.

O objetivo deste trabalho é o estudo dos gossans, visando a sua caracterização textural, mineralógica e geoquímica, e a investigação das fases suporte do cobre, chumbo e zinco após a total oxidação dos sulfetos desses metais. O problema do ouro será abordado aqui apenas do ponto de vista de sua associação com os demais metais. Um estudo específico sobre as formas de ocorrência de ouro nos gossans está em elaboração.

CONTEXTO GEOLÓGICO E MORFOCLIMÁTICO A região de Luziânia (Fig. 1) é constituída por rochas pertencentes ao Grupo Canastra, do Mesoproterozóico, que está contido no Cinturão de Dobramentos Brasília, na margem ocidental do Cráton do São Francisco. Na área considerada, compõe-se predominantemente de um pacote de metapelítos (filitos e xistos) de orientação NE, limitado a leste e a oeste por bandas miloníticas de zonas de cisalhamento (Hagemann 1989).

O Alvo Cabeça Seca está inserido em uma zona de cisalhamento afetada por intensa alteração hidrotermal. Nela os filitos são as rochas dominantes, de cor verde acinzentada a cinza escura, quando car* In memoriam

** Instituto de Geociências da Universidade de São Paulo - Caixa Postal 11348 bonosos, e de composição essencialmente quartzo-illítica, apresentando clorita, turmalina e opacos como acessórios. A feição estrutural mais marcante dessas rochas é o desenvolvimento de uma foliação milonítica de atitude média N20E, 30W (Barbosa et ai. 1990).

A mineralização primária apresenta nítido controle estrutural associado à evolução de uma zona de cisalhamento dúctil, e está relacionada à percolação de fluidos hidrotermais, com concentração de $\mathrm{Au}, \mathrm{Ag}$ e metais base. O minério é constituído por um pacote de filito bastante afetado pela alteração hidrotermal, em cujos planos de foliação alojam-se veios boudinados de quartzo esfumaçado e com sulfetos. Em alguns locais, os sulfetos são tão abundantes que formam verdadeiras lentes de minério maciço. Esses veios foram descritos como "charutos", apresentando-se mais ou menos descontínuos ao longo do comprimento, com dimensões que variam desde alguns centímetros até uma dezena de metros de comprimento, com espessura média da ordem de alguns decimetres. Dentre os sulfetos, o mais abundante é a pirita, que ocorre como cristais geralmente idiomórficos,. de 0,1 a $4 \mathrm{~mm}$, em agregados maciços, ou impregnando o filito milonitizado. Associam-se à pirita, a galena, a calcopirita e a esfalerita. Esses sulfetos ocorrem em massas irregulares de cristais distribuídos entre os grãos ou nas fraturas da pirita. Arsenopirita e pirrotita subordinadas. Finas partículas de ouro $(<0,05 \mathrm{~mm})$ distribuem-se principalmente nas microfraturas da pirita e arsenopirita, podendo também ocorrer em forma livre, associadas ao quartzo (Lacerda Neto \& Matos 1990).

Próximo à superfície, os "charutos" mineralizados estão oxidados, formando gossans. Neles misturam-se, em variadas proporções, dois tipos de materiais: uma massa de óxi-hidróxidos de ferro, de alteração dos sulfetos, e restos do filito com textura parcialmente conservada e fortemente ferruginizado.

O Alvo Cabeça Seca está localizado na bacia hidrográfica do rio São Bartolomeu, à margem direita do córrego Pamplona, seu afluente. O relevo ondulado, a altitudes em tomo de $900 \mathrm{~m}$, representa zona de dissecação da Superfície Sul-Americana (Braun 1971), que aparece no horizonte freqüentemente encouraçada, a altitudes superiores a 1000 m (Fig. 2). As extremidades aflorantes dos "charutos" gossânicos aparecem como pequenos ressaltos na paisagem, devido à sua maior resistência à erosão em relação ao filito encaixante.

O clima da região é característico das savanas tropicais, com duas estações contrastadas: uma seca, que corresponde ao outono e ao inverno, indo de abril a outubro, e outra úmida, com chuvas torrenciais, correspondente à primavera e ao verão. A temperatura média anual é de $20^{\circ} \mathrm{C}$. Os totais pluviométricos anuais oscilam entre 1300 e 1750 mm (Barbosa et ai. 1981).

AMOSTRAGEM E TÉCNICAS ANALÍTICAS Para este trabalho, foram utilizados dados de análises químicas fornecidos pela METAGO para 158 amostras coletadas nas cinco trincheiras que apresentaram os melhores resultados para $\mathrm{Au}$ e $\mathrm{Ag}$ na área do Alvo Cabeça Seca. Essas amostras foram analisadas para: $\mathrm{Al}, \mathrm{Fe}^{2+}, \mathrm{Fe}^{3+}, \mathrm{Si}$, Perda ao Fogo (PF) por via úmida, Be, Bi, B, Ti, Sn, Mo, V, Ag, Zr, 


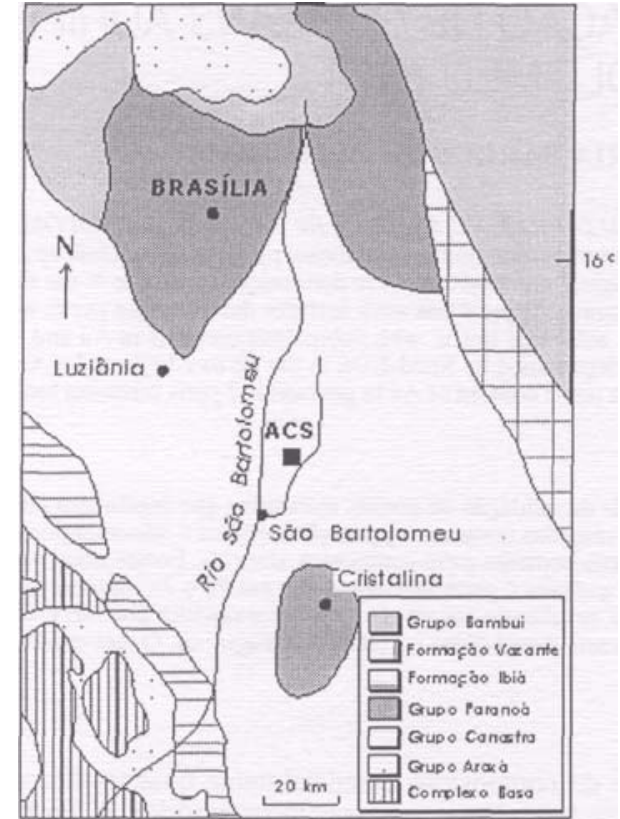

Figura l - Mapa geológico da região de Luziânia, estado de Goiás (simplificado de Schobbenhaus et ai. 1981).

Y, La, Sr, Nb, Ba, Ga por espectrografia de emissão óptica, e Ag, Cu, $\mathrm{Pb}, \mathrm{Zn}, \mathrm{Au}$ por espectrofotometria de absorção atômica. O tratamento estatístico dos dados químicos foi feito através do programa Statgraphics.

Duas trincheiras que cortem o minério oxidado (T6 e T8) foram re-amostradas para as finalidades deste trabalho. Foram retiradas 21 amostras representativas das diferentes fácies reconhecíveis macroscopicamente, para estudos mineralógicos e geoquímicos de detalhe. Essas trincheiras, de 1 a $2 \mathrm{~m}$ de profundidade, não expuseram o perfil de alteração completo, mas apenas seu topo, de modo que as diferentes fácies amostradas correspondem a horizontes de gossan, completamente oxidados.

A caracterização mineralógica dos gossans foi realizada por microscopia óptica em seções delgadas e polidas, e por difratometria de raios X (difratômetro Philips PW 1390, usando radiação $\mathrm{CuK} \alpha$ ). Para determinar o conteúdo de $\mathrm{A} 1 \mathrm{OOH}$ da goethita, em cinco amostras foi adicionado $\mathrm{Pb}\left(\mathrm{NO}_{3}\right)_{2}$ como padrão interno, e medido com precisão o espaçamento (111), segundo o procedimento descrito por Fitzpatrick \& Schwertmann (1982). Para uma amostra, foi obtido um espectro de infravermelho de $4000 \mathrm{a} 400 \mathrm{~cm}^{-1} \mathrm{em}$ um equipamento Nicolet 510 FTIR, usando pastilha confeccionada com $\mathrm{KBr}$ na proporção aproximada de $2 \mathrm{mg}$ de amostra para $100 \mathrm{mg}$ de matriz.

Em oito amostras foi realizada uma investigação das fases amorfas, através da dosagem de $\mathrm{Fe}, \mathrm{Cu}, \mathrm{Pb}$ e $\mathrm{Zn}$ em alíquotas submetidas a ataque $\mathrm{HF}-\mathrm{HNO}_{3}$ (teores totais) e alíquotas tratadas por ácido oxálicooxalato de amônia a pH 3, por 4 horas, na obscuridade (McKeague \& Day 1966).

Três amostras foram selecionadas para análise dos óxi-hidróxidos de ferro ao microscópio eletrônico de varredura equipado com microanalisador (sistema EDS). Foram dosados $\mathrm{Si}, \mathrm{Al}, \mathrm{Fe}, \mathrm{Cu}, \mathrm{Pb}, \mathrm{Zn}$ e $\mathrm{Mn}$.

\section{ASPECTOS MINERALÓGICOS E TEXTURAIS DOS GOS-}

SANS Macroscopicamente os gossans são como uma mistura de material ferruginoso oxidado (polo ferruginoso) com material rochoso alterado (polo rochoso). Dada a heterogeneidade do conjunto, as fácies são muito diversificadas: maciça, escoriácea, brechóide, xistosa, laminar, sacaróide etc. As cores variam do amarelo intenso ao quase preto, passando por tons marrons e avermelhados, e o brilho é geralmente metálico.

A identificação óptica em seções delgadas e polidas dos minerais das 21 amostras coletadas, apoiada nos dados de difratometria de raios X (Tab. 1), permitiu reconhecer quartzo, goethita e illita como mais abundantes, hematita como acessório, e raros grãos xenomórficos de $\mathrm{Au}$. O teor médio de $\mathrm{A} 1 \mathrm{OOH}$ na goethita foi estimado em $5 \% \mathrm{~A} 1 \mathrm{OOH}$ molar.

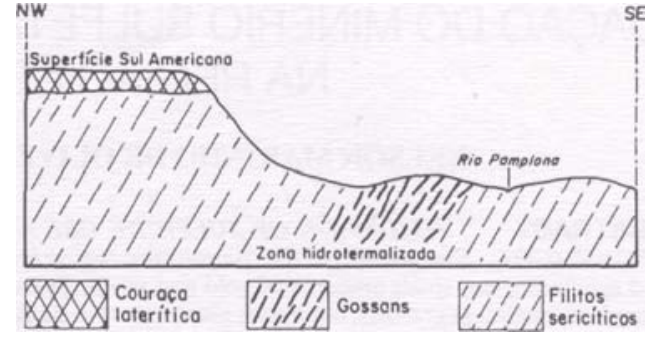

Figura 2 - Seção topográfica esquemática da região de São Bartolomeu, mostrando a zona de dissecação da Superficie Sul-Americana.

Tabela 1 - Composição mineralógica estimada por difratometria de raios $X . Q z=$ quartzo, Gt = goethita, $\mathrm{Ill}=$ illita, $\mathrm{Hm}=$ hematita, () Traços.

\begin{tabular}{|cc|}
\hline Amostra & Minerais presentes \\
T8-1 & Qz, Gt, Ill, (Ht) \\
T8-2 & Qz, Gt, III, Ht \\
T8-3 & Qz, Gt, III, Ht \\
T8-4 & Qz, Gt, Ill, (Ht) \\
T8-5 & Qz, Gt, Ill, (Ht) \\
T8-6 & Qz, Gt, III, (Ht) \\
T8-7 & Qz, Gt, III, Ht \\
T8-8 & Qz, Gt, III, (Ht) \\
T8-9 & Qz, Gt, Ill \\
T8-10 & Gt, Qz, (III) \\
T6-1 & Gt, Qz, III, (Ht) \\
T6-2 & Qz, Gt, III \\
T6-3 & Qz, Gt, III, (Ht) \\
T6-4 & Qz, Gt, III, (Ht) \\
T6-5 & Qz, Gt, III, (Ht) \\
T6-6 & Qz, Gt, Ill, (Ht) \\
T6-7 & Gt, Qz, Ht, (III) \\
T6-8 & Gt, Qz, (III), (Ht) \\
T6-9 & Qz, Gt, III, (Ht) \\
T6-10 & Qz, Gt, III, Ht \\
T6-11 & Gt, Qz, (III) \\
\hline
\end{tabular}

A goethita é microcristalina, em texturas pseudomórficas tipo boxwork, replicando a morfologia cúbica dos cristais euédricos de pirita. Nesses casos, foi precipitada in situ, ao longo dos planos de clivagem da pirita, num estágio relativamente precoce da oxidação, antes que a totalidade dos sulfetos tivesse se dissolvido. Os núcleos do reticulado formado apresentam-se geralmente vazios (Fig. 3A), o que dá grande porosidade aos gossans. Em alguns casos, restos de pirita inalterada permanecem nesses núcleos (Fig. 3B). Não foram observadas as feições características das substituições pseudomórficas de outros sulfetos por goethita.

É comum a presença de goethita botrioidal, precipitada a partir do Fe coloidal, nas bordas internas das cavidades dos boxworks (Fig. 3C). Essas estruturas botrioidais podem apresentar-se zonadas, estando a goethita intercalada com hematita (Fig. 3D). Em canais de dissolução, a goethita pode precipitar sob forma fibrorradiada, perpendicular às paredes. As margens internas desses canais revestidos por goethita aparecem comumente bordejadas por glóbulos de hematita (Fig. 4A). Outra forma comum de ocorrência de goethita é como plasmas opticamente homogêneos, não guardando qualquer relação com as texturas dos sulfetos pré-existentes (Fig. 4B).

Associadas a quaisquer dessas formas de goethita, podem ocorrer partículas de ouro de frações de milímetros de dimensão (Fig. 4B). O quartzo, sempre presente, forma agregados policristalinos cujos contornos são sublinhados pelos óxidos de ferro (Fig. 4C). Nas fácies ricas em illita, o plasma ferruginoso aparece orientado segundo as clivagens do filossilicato (Fig. 4D ).

No espectro infravermelho obtido com a amostra de gossan T6/8 (Fig. 5), verificou-se a presença de uma banda bem marcada a 3130 cm-' correspondente à vibração do estiramento $\mathrm{OH}$ da goethita. Uma banda menos intensa a $3600 \mathrm{~cm}-{ }^{-}$pode ser atribuída aos grupos hidroxila de superfície. As bandas correspondentes às ligações $\mathrm{OH}$, que vibram respectivamente para dentro e para fora em relação ao plano (100), são bandas diagnosticas e provêm informação sobre a cristalinidade e a intensidade da substituição do Fe por Al (Cambier 

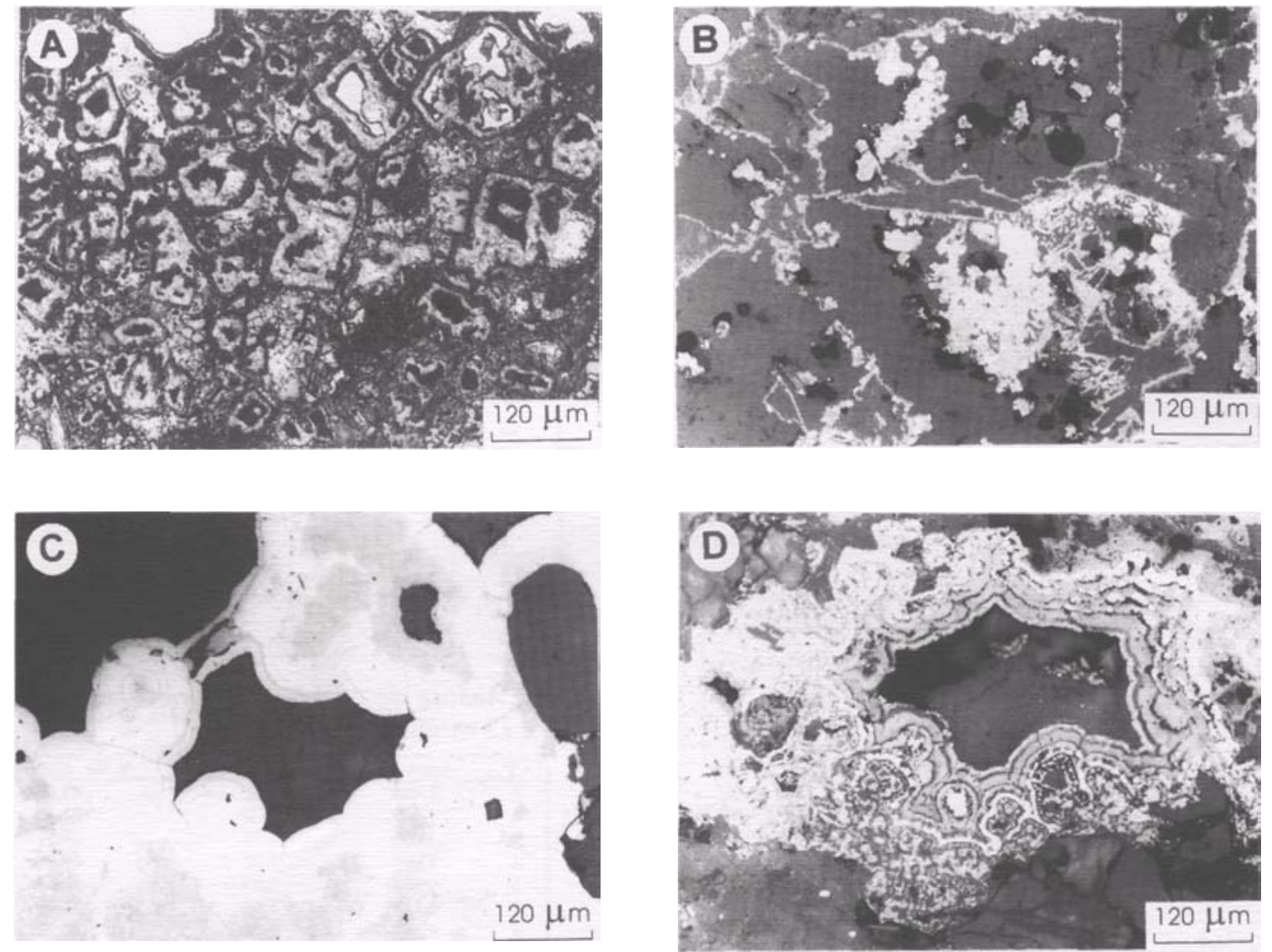

Figura 3 -A - Fotomicrografia de seção polida, mostrando textura boxwork quadrangular, com pirita remanescente. B - Fotomicrografia de seção polida, mostrando contornos de pirita pseudomorfizados porgoethita. C - Fotomicrografia de seção polida, mostrando goethita coloforme, preenchendo cavidade. D. Fotomicrografia de seção polida, mostrando estruturas botrioidias de goethita (cinza) alternando com hematita (branco).
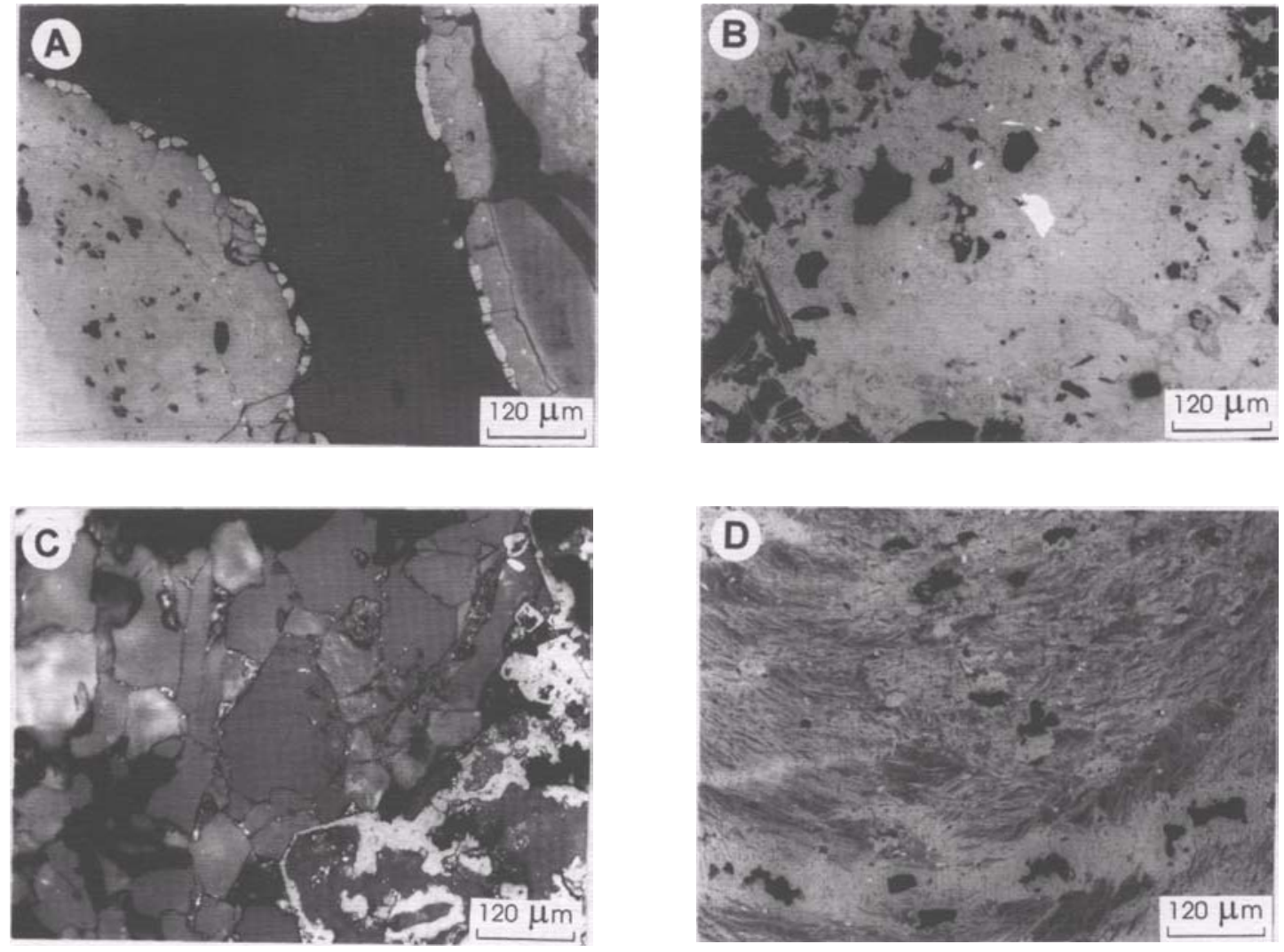

Figura 4 - A. Fotomicrografia de seção polida, mostrando goethitafibrorradiada, perpendicular às paredes de um canal. Glóbulos de hematita aparecem adendos à goethita. B. Fotomicrografia de seção polida, mostrando partícula de ouro mergulhada no plasma goethítico homogêneo. C. Fotomicrografia de seção polida, mostrando grãos de quartzo sublinhados por goethita. D. Fotomicrografia de seção polida, mostrando plasma ferruginoso orientado segundo as clivagens da illita 


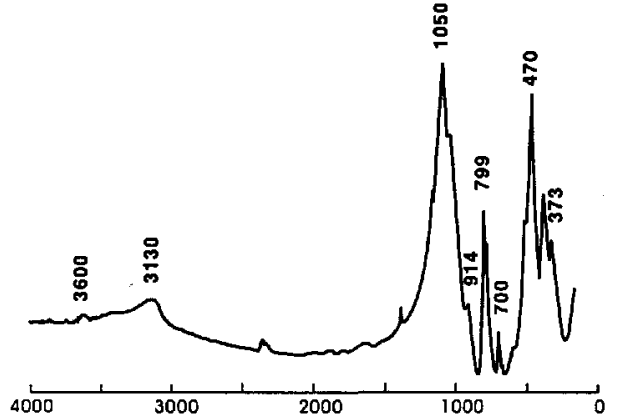

COMPRIMENTO DE ONDA (cm"1)

Figura 5 - Espectro infravermelho para a amostra T6-8.

Tabela 2 - Composição química dos gossans. Elementos maiores (\% em peso), $n=158$.

\begin{tabular}{|ccccc|}
\hline & Máximo & Mínimo & Média & Desvio-padrão \\
\hline $\mathrm{Al}_{2} \mathrm{O}_{3}$ & 26,0 & 5,9 & 14,2 & 4,1 \\
$\mathrm{FeO}$ & 0,5 & 0,01 & 0,3 & 0,1 \\
$\mathrm{Fe}_{2} \mathrm{O}_{3}$ & 67,7 & 8,8 & 40,6 & 13,4 \\
$\mathrm{SiO}_{2}$ & 61,5 & 10,2 & 32,7 & 10,5 \\
$\mathrm{PF}$ & 10,8 & 3,7 & 7,2 & 1,9 \\
\hline
\end{tabular}

Tabela 3 - Composição mineralógica (\% em peso) dos gossans calculada a partir dos dados químicos, $n=158$.

\begin{tabular}{|ccccc|}
\hline & Mínimo & Máximo & Média & Desvio-padrão \\
\hline Quartzo & 0,1 & 37,9 & 17,1 & 7,2 \\
Illita & 10,3 & 66,9 & 33,7 & 11,6 \\
Ox-hidr. Fe & 10,1 & 79,1 & 46,9 & 15,5 \\
\hline
\end{tabular}

1986). No caso da amostra estudada, as bandas situam-se a $914(\mathrm{\delta OH})$ e $799(\gamma \mathrm{OH}) \mathrm{cm}^{-1}$. A separação entre essas duas bandas, de $115 \mathrm{~cm}^{-1}$, indicaria para essa amostra teores de $\mathrm{A} 1 \mathrm{OOH}$ em torno de $15 \%$ (Schulze \& Schwertmann 1987), superior à média de 5\% estimada por difratometria de raios X. As demais bandas presentes, a cerca de 1050 , 700 e $470 \mathrm{~cm}^{-1}$, correspondem à muscovita (Stubican \& Roy 1961).

QUIMISMO DOS GOSSANS Química total A Tabela 2 mostra os parâmetros estatísticos da composição química dos gossans quanto aos elementos maiores. Em média, cerca de $41 \%$ em peso correspondem aos óxidos de ferro, e $47 \%$ à soma da silica e alumina. Levando em conta que os principais minerais presentes são quartzo, illita, goethita e hematita, e que a goethita possui em média $5 \%$ molar de $\mathrm{A} 1 \mathrm{OOH}$, é possível estimar quantitativamente a composição mineralógica, o que é mostrado na Tabela 3. Os grandes intervalos de variação de teor dos três minerais predominantes confirmam a sugestão de que os gossans são misturas de um polo ferruginoso dominante (óxi-hidróxidos de ferro) com um polo rochoso (quartzo e illita). $\mathrm{Na}$ maior parte das amostras, o teor de água atribuído aos óxidos de ferro supera sua quantidade estequiométrica na goethita, o que indica a existência de fases ferruginosas mais hidratadas, talvez amorfas ou mal cristalizadas.

A variação composicional com relação aos elementos maiores é acompanhada por amplos intervalos de variação dos teores dos elementos-traços (Tab. 4). Os teores de Bi, Be, Mo, Sn, Zr, Y, Sr, Nb, Ba, $\mathrm{Zr}$ e Ga estão sempre muito próximos ao limite de detecção do método analítico e, por isso, não serão considerados na interpretação. B, Ti, V, La e Sc apresentam valores da ordem de grandeza da média crustal. Apenas para cinco elementos-traços - $\mathrm{Ag}, \mathrm{Cu}, \mathrm{Pb}, \mathrm{Zn}$ e Au - as médias e as medianas são significativamente elevadas. Chama a atenção a grande amplitude das faixas de variação dos teores desses elementos, e o fato de que as medianas são geralmente inferiores às médias, indicando que existem amostras com valores anômalos bem elevados. Assim, embora em média a ordem de abundância desses metais nos gossans seja $\mathrm{Pb}(855 \mathrm{ppm})>\mathrm{Zn}(624 \mathrm{ppm})>\mathrm{Cu}(135 \mathrm{ppm})>\mathrm{Ag}(4 \mathrm{ppm})$ $>\mathrm{Au}(2 \mathrm{ppm})$, em algumas amostras essa ordem pode mudar, o que, de fato, acontece em relação aos teores de $\mathrm{Pb}$ e $\mathrm{Zn}$, cujos intervalos de variação dos teores se sobrepõem.

Com a finalidade de investigar as relações entre o comportamento dos vários elementos analisados, foi aplicada ao conjunto de dados das 158 amostras a análise de componentes principais modo Q. As
Tabela 4 - Composição química dos gossans. Elementos-traços (ppm), $n=158$

\begin{tabular}{|c|ccccc|}
\hline Elemento & Máximo & Mínimo & Media & Mediana & Desvio-padrão \\
\hline $\mathrm{Ag}$ & 83 & 0,5 & 3,9 & 2 & 7,1 \\
$\mathrm{Cu}$ & 350 & 10 & 135 & 120 & 68,5 \\
$\mathrm{~Pb}$ & 3200 & 35 & 855 & 670 & 576 \\
$\mathrm{Zn}$ & 2565 & 25 & 624 & 215 & 680 \\
$\mathrm{Au}$ & 29 & 0,1 & 2 & 0,4 & 4,2 \\
$\mathrm{~B}$ & 150 & 7 & 34 & 30 & 26 \\
$\mathrm{Bi}$ & 7 & 7 & 7 & 7 & 0 \\
$\mathrm{Be}$ & 2 & 0,7 & 1,4 & 1,5 & 0,3 \\
$\mathrm{Ti}$ & 7000 & 700 & 2342 & 3000 & 1374 \\
$\mathrm{Mo}$ & 7 & 2,5 & 3,6 & 3,5 & 0,5 \\
$\mathrm{Sn}$ & 7 & 5 & 6 & 7 & 1 \\
$\mathrm{~V}$ & 200 & 10 & 70 & 70 & 33 \\
$\mathrm{Zs}$ & 200 & 50 & 104 & 100 & 34 \\
$\mathrm{Y}$ & 70 & 10 & 39 & 50 & 18 \\
$\mathrm{La}$ & 70 & 14 & 26 & 20 & 12 \\
$\mathrm{Sc}$ & 70 & 7 & 17 & 15 & 8 \\
$\mathrm{~S} r$ & 70 & 50 & 70 & 70 & 2,7 \\
$\mathrm{Nb}$ & 10 & 7 & 8 & 7 & 1,4 \\
$\mathrm{Ba}$ & 500 & 50 & 269 & 300 & 116 \\
$\mathrm{Ga}$ & 30 & 3,5 & 17 & 15 & 7,4 \\
\hline
\end{tabular}

Tabela 5 - Análise de componentes principais modo Q para 158 amostras e 13 variáveis.

\begin{tabular}{|cccc|}
\hline CP & Autovalor & \% Variância & \% Var. acumulada \\
\hline 1 & 5,466 & 42,05 & 42,05 \\
2 & 1,449 & 11,15 & 53,19 \\
3 & 1,089 & $\mathbf{8 , 3 8}$ & 61,57 \\
4 & 1,069 & 8,22 & 69,79 \\
5 & 0,908 & 6,99 & 76,78 \\
6 & 0,738 & 5,68 & 82,46 \\
7 & 0,554 & 4,26 & 86,72 \\
8 & 0,521 & 4,01 & 90,72 \\
9 & 0,369 & 2,84 & 93,56 \\
10 & 0,327 & 2,52 & 96,08 \\
11 & 0,281 & 2,16 & 98,23 \\
12 & 0,171 & 1,31 & 99,55 \\
13 & 0,058 & 0,45 & 100,00 \\
\hline
\end{tabular}

variáveis consideradas foram $\mathrm{Ag}, \mathrm{Cu}, \mathrm{Pb}, \mathrm{Zn}, \mathrm{Au}, \mathrm{B}, \mathrm{Ti}, \mathrm{V}, \mathrm{La}, \mathrm{Sc}$, $\mathrm{Al}_{2} \mathrm{O}_{3}$ e $\mathrm{Fe}_{2} \mathrm{O}_{3}$, as duas últimas representando a composição do polo rochoso e a do ferruginoso, respectivamente. A Tabela 5 mostra a porcentagem da variância explicada para as 13 componentes principais calculadas a partir dos autovalores extraídos da matriz de partida. A CPI explica $42 \%$ da variância total e a CP2 explica mais de $11 \%$. Assim, o modelo de duas componentes principais, explicando mais de $50 \%$ da variância total, mostrou-se adequado para descrever o comportamento das variáveis. A figura 6 ilustra graficamente a composição de cada uma das duas componentes. A CPI é carregada positivamente nos elementos que acompanham o $\mathrm{Fe}_{2} \mathrm{O}_{3}(\mathrm{~Pb}, \mathrm{Zn}, \mathrm{Cu}, \mathrm{Au}$ e $\mathrm{Ag})$ e negativamente nos que acompanham o $\mathrm{Al}_{2} \mathrm{O}_{3}$ ( $\mathrm{B}, \mathrm{Ti}, \mathrm{V}, \mathrm{Y}, \mathrm{La}$ e Sc), opondo o polo ferruginoso, derivado da alteração dos sulfetos, ao polo alumino-silicatado, que representa os minerais da ganga pouco ou não alterados. Já a CP2 apresenta os maiores coeficientes positivos de $\mathrm{Au}$ e $\mathrm{Ag}$ e negativos de $\mathrm{Pb}$ e $\mathrm{Zn}$. Essa componente opõe, entre as amostras originalmente ricas em sulfetos, as ricas em $\mathrm{Au}$ e $\mathrm{Ag}$ às ricas em $\mathrm{Pb}$ e Zn.

Para detalhar um pouco mais o comportamento do ouro em relação à prata e aos metais calcófilos, foram calculados os coeficientes de correlação do $\mathrm{Au}$ com relação a $\mathrm{Ag}, \mathrm{Cu}, \mathrm{Pb}$ e $\mathrm{Zn}$ para sub-populações definidas em função de valores mínimos de $\mathrm{Fe}_{2} \mathrm{O}_{3}$ (Tabela 6). Com o aumento do limite mínimo de $\mathrm{Fe}_{2} \mathrm{O}_{3}$, vão sendo consideradas subpopulações de amostras onde o polo ferruginoso predomina e onde, portanto, essas correlações vão sofrendo cada vez menos o efeito diluidor do polo silicatado. Deve-se assim esperar que, em direcão aos valores maiores de $\mathrm{Fe}_{2} \mathrm{O}_{3}$, as correlações apareçam melhor. De fato, para Ag, o coeficiente de correlação com Au é maior nas amostras mais ricas em $\mathrm{Fe}_{2} \mathrm{O}_{3}$, mas os demais elementos ficam abaixo do nível de significância considerado.

$\mathrm{Da}$ análise multivariada dos dados químicos, conclui-se que $\mathrm{Pb}, \mathrm{Zn}$, $\mathrm{Cu}, \mathrm{Au}$ e $\mathrm{Ag}$ estão preferencialmente associados às amostras de gossans mais ricas em $\mathrm{Fe}_{2} \mathrm{O}_{3}$, derivadas da oxidação de sulfetos (galena, esfalerita, calcopirita e principalmente pirita). Porém, dentro desse grupo, podem-se identificar dois sub-grupos, $\mathrm{Pb}-\mathrm{Zn}-\mathrm{Cu}$ e $\mathrm{Au}-\mathrm{Ag}$, que se comportam de modo independente um do outro.

Química pontual Com a finalidade de detalhar o estudo da distribuição de $\mathrm{Pb}, \mathrm{Zn}$ e $\mathrm{Cu}$ nas fases ferruginosas dos gossans, 
Tabela 6 - Coeficientes de correlação Pearson. Em negrito, quando significativo ao nivel de $99 \%$.

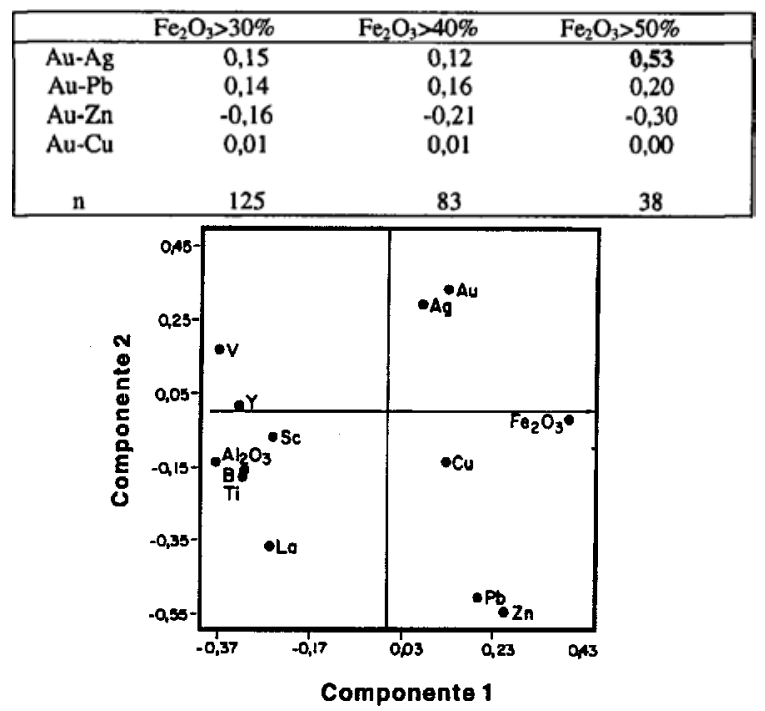

Figura 6 - Projeção das variáveis nos eixos da primeira (CP1) e segunda (CP2) componentes principais.

Tabela 7 - Análises por MEV-EDS (\% em peso) para a amostra T6/4. n.d. $=$ não detectado.

\begin{tabular}{|c|c|c|c|c|c|c|c|}
\hline T6-4 & $\mathrm{Al}_{2} \mathrm{O}_{3}$ & $\mathrm{SiO}_{2}$ & $\mathrm{Fe}_{2} \mathrm{O}_{3}$ & $\mathrm{Cu}_{2} \mathrm{O}$ & $\mathrm{ZnO}$ & $\mathrm{PBO}$ & MnO \\
\hline $\mathrm{Zl} / 1$ & 0,51 & 2,83 & 77,02 & n.d. & 0,28 & 0,02 & n.d. \\
\hline $\mathrm{Z} 1 / 2$ & 0,5 & 3.78 & 73,11 & 0.20 & & & 0.09 \\
\hline $21 / 3$ & 0.73 & 1,31 & 77,50 & 0,05 & 0.46 & 0,19 & n.d. \\
\hline Média & 0,58 & 2,64 & 75,88 & 0,09 & 0,41 & 0,07 & 0,03 \\
\hline $22 / 1$ & 1,83 & 6.55 & 66,68 & 0.11 & 0,05 & 0,37 & n.d. \\
\hline $\mathrm{Z} 2212$ & 2,2 & 2,8 & 68,68 & 0 & 0,07 & n.d. & 0.06 \\
\hline $\mathrm{Z} 2 / 3$ & 1,61 & 3,86 & 66,84 & n.d. & 0,05 & 0,05 & n.d. \\
\hline Média & 1,90 & 4,40 & 67,40 & 0,08 & 0,06 & 0,14 & 0,02 \\
\hline $\mathrm{Z} 3 / 1$ & 0.59 & 2,36 & 79,58 & 0,0 & 0.2 & 0.15 & 0.09 \\
\hline $\mathrm{Z3} 32$ & 1,15 & 4,07 & 77,99 & n.d & 0,08 & 0,24 & 0,01 \\
\hline $\mathrm{Z} 33$ & 0,45 & 2,63 & 84,39 & n.c & 0,22 & 0,20 & n.d. \\
\hline Média & 0.73 & 3.02 & 80,65 & 0.02 & 0,17 & 0,20 & 0,03 \\
\hline $\mathrm{ZA/1}$ & 7,42 & 9,35 & 57 , & n. & 0.2 & 0. & n. \\
\hline $\mathrm{ZA} / 2$ & & 2,4 & 72,4 & 0,1 & 0,05 & 0,02 & 0,02 \\
\hline$Z A B$ & 2. & 3,7 & 71. & 0,0 & 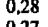 & 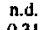 & 0 \\
\hline$Z 4 / 4$ & & & & & & & \\
\hline $\mathrm{Z} 4 / \mathrm{s}$ & 1,73 & 1,9 & SWo & & .16 & 0,07 & n.d. \\
\hline Média & 3,08 & 3,91 & 67,74 & 0,07 & 0.21 & 0,17 & 0,02 \\
\hline $\mathbf{z} 5 / 1$ & 0.5 & 2.6 & 75.5 & n.o & 0.17 & 0. & \\
\hline $\mathrm{zs} / 2$ & & a & & & 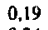 & 0,2 & 0,09 \\
\hline $25 / 3$ & 0 & 3,79 & 77,29 & 0,02 & $\overrightarrow{0}$ & 0,4 & 0,09 \\
\hline Média & 0,65 & 3,13 & 75,24 & 0.05 & 0,23 & 0,22 & 0,06 \\
\hline
\end{tabular}

definidas ao microscópio óptico por texturas e cores diferenciadas, foram efetuadas análises pontuais ao MEV-EDS sobre lâmina delgada/polida em 3 amostras. Os resultados, sob forma de óxidos, estão apresentados nas Tabelas 7, 8 e 9. Para cada amostra, nas zonas de plasma ferruginoso identificadas opticamente como homogêneas $(Z 1$, $\mathrm{Z} 2, \mathrm{Z} 3$ etc), foram realizadas de 3 a 10 análises pontuais $(\mathrm{Z1} / 1, \mathrm{Zl} / 2$ etc) e calculadas as médias.

A análise dos dados indica que os plasmas ferruginosos são bastante heterogêneos quanto à composição química, mesmo em zonas opticamente homogêneas. As grandes variações nos teores de $\mathrm{Fe}_{2} \mathrm{O}_{3}$ de uma zona homogênea para outra, e mesmo dentro de uma mesma zona homogênea, deve-se provavelmente à porosidade do material, além de uma variação nas quantidades relativas de hematita e goethita. De modo geral, as zonas que aparecem na lâmina delgada como mais opacas, como, por exemplo, a Z3 da amostra T6/4, apresentam teores de ferro mais alto que as zonas mais amareladas e transparentes adjacentes, como a Z2 da mesma amostra (Tab.7). Essas zonas mais opacas, com teores de $\mathrm{Fe}$ mais elevados, correspondem as relativamente mais ricas em hematita do que goethita. A principal impureza dos plasmas ferruginosos analisados é a silica, que deve representar quartzo finamente dividido misturado aos óxi-hidróxidos de ferro. Os teores de $\mathrm{Al}_{2} \mathrm{O}_{3}$, geralmente inferiores a $1 \%$, podem ser atribuídos, pelo menos em parte, à substituição do Fe por Al na estrutura da goethita. O Mn está localizadamente presente nos pontos dosados e, nesses casos, geralmente em quantidades inferiores à média crustal.
Tabela 8 - Análises por MEV-EDS (\% em peso) para a amostra T6/5. n.d. $=$ não detectado.

\begin{tabular}{|c|c|c|c|c|c|c|c|}
\hline T6-5 & $\mathrm{Al}_{2} \mathrm{O}_{3}$ & $\mathrm{SiO}_{2}$ & $\mathrm{Fe}_{2} \mathrm{O}_{3}$ & $\mathrm{Cu}_{2} \mathrm{O}$ & $\mathrm{ZnO}$ & $\mathrm{PbO}$ & $\mathrm{MnO}$ \\
\hline $\mathrm{Zl} / \mathrm{I}$ & 0,34 & 2,17 & 76,33 & 0,17 & 0,04 & 0,60 & n.d. \\
\hline $\mathrm{Z} 1 / 2$ & 0,66 & 2,65 & 75,52 & 0,06 & 0,34 & n.d. & n.d. \\
\hline $\mathrm{Z} 1 / 3$ & 0,93 & 2,72 & 75,89 & 0,06 & 0,29 & 0,27 & n.d. \\
\hline $\mathrm{Zl} 1 / 4$ & 0,77 & 3,07 & 76,95 & n.d. & 0,06 & 0,54 & 0,04 \\
\hline $\mathrm{Z} 1 / 5$ & 0.44 & 2,99 & 77.86 & 0.17 & 0.13 & 0,43 & n.d. \\
\hline $21 / 6$ & 0,92 & 2,86 & 67,93 & n.d. & 0,27 & a.d. & 0,03 \\
\hline $\mathbf{z} 1 / n$ & 1,45 & 3,57 & 78,23 & 0,14 & 0,34 & 0,42 & n.d. \\
\hline Média & 0,67 & 2,74 & 75,08 & 0,08 & 0,19 & 0,31 & 0,01 \\
\hline $\mathrm{z} 2 / 1$ & 3,64 & 5,05 & 70,72 & 0,04 & n.d. & 0,31 & n.d. \\
\hline $\mathrm{Z} 22 / 2$ & 2,40 & 1,87 & 74,02 & n.d. & 0,15 & 0,20 & n.d. \\
\hline $22 / 3$ & 7,58 & 9,33 & 56,30 & 0,29 & 0,17 & 0,19 & 0,06 \\
\hline $22 / 4$ & 2,34 & 0,85 & 51,70 & n.d. & n.d. & 0,07 & n.d. \\
\hline $22 / 5$ & 4,38 & 4,10 & 65,78 & n.d. & 0,24 & 0,41 & n.d. \\
\hline $22 / 6$ & 4,71 & 5,56 & 68,29 & 0,19 & 0,31 & 0,36 & n.d. \\
\hline $22 \pi$ & 4,28 & 5,17 & 69,06 & n.d. & 0,20 & 0,63 & 0,05 \\
\hline $\mathrm{Z} 2 / 8$ & 4,39 & 6,06 & 68,24 & 0,03 & 0,32 & 0,69 & n.d. \\
\hline 2219 & 2,14 & 4,18 & 68,19 & n.d. & 0,38 & 0,07 & 0,03 \\
\hline $\mathrm{z} 2 / 10$ & 6,88 & 9,39 & 61.00 & 0.13 & 0.25 & 0,36 & n.d. \\
\hline Média & 4,28 & 5,16 & 65,33 & 0,07 & 0,20 & 0.33 & 0,01 \\
\hline $\mathrm{Z} 3 / 1$ & 1,77 & 1,19 & 72,48 & n.d. & 0,13 & 0,68 & n.d. \\
\hline $23 / 2$ & 0,83 & 0,79 & 54,44 & 0,09 & 0,22 & 0,16 & n.d. \\
\hline $\mathrm{z} 3 / 3$ & 3.13 & 1,95 & 69,42 & 0,21 & 0.35 & 0,51 & 0.23 \\
\hline $\mathrm{z} 3 / 4$ & 2,73 & 0,91 & 68,79 & 0,01 & 0,28 & 0,31 & 0.15 \\
\hline Média & 2,12 & 1,21 & 66,28 & 0,08 & 0,25 & 0,42 & 0,10 \\
\hline
\end{tabular}

Tabela 9 - Análises por MEV-EDS (\% em peso) para a amostra T6/7. n.d. $=$ não detectado.

\begin{tabular}{|c|c|c|c|c|c|c|c|}
\hline T6-7 & $\mathrm{Al}_{2} \mathrm{O}_{3}$ & $\mathrm{SiO}_{2}$ & $\mathrm{Fe}_{2} \mathrm{O}_{3}$ & $\overline{\mathrm{Cu}_{2} \mathrm{O}}$ & $\mathrm{ZnO}$ & $\mathrm{PbO}$ & $\mathrm{MnO}$ \\
\hline $\mathrm{z} 2 / 1$ & 0,15 & 1,67 & 85,96 & 0,02 & 0,19 & 0,39 & 0,12 \\
\hline $\mathrm{Z} 2 / 2$ & 1,21 & 3,82 & 89,21 & 0,03 & 0,05 & 0,54 & 0,01 \\
\hline $22 / 3$ & 0,31 & 0,57 & 82,97 & n.d. & n.d. & 0,02 & 0,22 \\
\hline $\mathrm{Z} 2 / 4$ & 1,09 & 3,18 & 86,52 & n.d. & 0,29 & 0,53 & n.d. \\
\hline $\mathrm{Z} 225$ & 1,27 & 2,53 & 70,03 & n.d. & 0,02 & 0,71 & 0,15 \\
\hline $22 / 6$ & 0,55 & 1,23 & 83,20 & 0,24 & 0,06 & 0,23 & 0,11 \\
\hline $\mathrm{z} 27$ & 0,55 & 1,33 & 85,69 & 0,02 & n.d. & n.d. & 0,01 \\
\hline $\mathrm{Z} 2 / 8$ & 0,47 & 1,96 & 84,67 & 0,17 & 0,30 & 0,21 & n.d. \\
\hline Média & 0,70 & 2,04 & 83,52 & 0,06 & 0,11 & 0,33 & 0,08 \\
\hline $23 / 1$ & 0,38 & 0,45 & 74,92 & 0,12 & 0,47 & 0,30 & 0,35 \\
\hline $\mathrm{z} 3 / 2$ & 0,37 & 0,72 & 85,96 & 0,20 & n.d. & 0,09 & 0,23 \\
\hline $\mathrm{z} 3 / 3$ & 0,29 & 1,03 & 85,10 & n.d. & 0,24 & 0,04 & 0,37 \\
\hline $\mathrm{Z3} / 4$ & 1,69 & 2,24 & 78,68 & 0,07 & 0,75 & 1,63 & n.d. \\
\hline $\mathrm{Z3} / 5$ & 0,32 & 1,21 & 85,37 & 0,09 & 0,34 & 0,12 & 0,06 \\
\hline $\mathrm{z} 3 / 6$ & 0,44 & 1,39 & 86,17 & n.d. & 0,23 & 0,34 & 0,04 \\
\hline Módia & 0.58 & 117 & 8270 & 0,08 & 0.34 & 0,42 & 0,18 \\
\hline
\end{tabular}

Tabela 10 - Teores totais $(T)$, teores de amorfos $(O)$ e porcentagem de amorfos (O/T) para $\mathrm{Fe}_{2} \mathrm{O}_{3}(\%), \mathrm{PbO}$ (ppm), $\mathrm{CuO}$ (ppm) e $\mathrm{ZnO}$ (ppm) nos gossans.

\begin{tabular}{|c|c|c|c|c|c|c|c|}
\hline & $\mathrm{Fe}_{2} \mathrm{O}_{3}$ & & PhO & & $\mathrm{CuO}$ & & $\mathrm{ZnO}$ \\
\hline & $\begin{array}{lll}T & 0 & 0 / T\end{array}$ & $T$ & $\begin{array}{ll}0 & 0 / T\end{array}$ & $\mathbf{T}$ & $0 \quad 0 / T$ & & $0 \quad 0 / T$ \\
\hline T6-1 & $\begin{array}{lll}51,4 & 0,9 & 1,8\end{array}$ & 1876 & $\begin{array}{ll}38 & 2,0\end{array}$ & 244 & $\begin{array}{ll}6 & 2.5\end{array}$ & 1628 & 664,1 \\
\hline T6-3 & $\begin{array}{lll}45.8 & 1,6 & 3.5\end{array}$ & 897 & $61 \quad 6,8$ & 174 & $\begin{array}{ll}6 & 3,4\end{array}$ & 1036 & 585,6 \\
\hline T6-11 & $\begin{array}{llll}58,7 & 3,3 & 5,6\end{array}$ & 3497 & 3469.9 & 136 & $14 \quad 10,3$ & 1004 & 868,6 \\
\hline T8-1 & $\begin{array}{llll}48,9 & 5,5 & 11,2\end{array}$ & 862 & $108 \quad 12,5$ & 329 & 267.9 & 268 & $\begin{array}{ll}35 & 13,1\end{array}$ \\
\hline TB-2 & $\begin{array}{llll}33,6 & 5,3 & 15,8\end{array}$ & 1045 & 36534,9 & 143 & $21 \quad 14,5$ & 135 & $25 \quad 18,5$ \\
\hline T8-4 & $40,6 \quad 5,3 \quad 13,1$ & 649 & 11117,1 & 208 & $\begin{array}{ll}28 & 13,5\end{array}$ & 352 & $51 \quad 14,5$ \\
\hline 785 & $45,0 \quad 4,1 \quad 9,1$ & 654 & $48 \quad 7,3$ & 271 & $16 \quad 5,9$ & 331 & $42 \quad 12,7$ \\
\hline T8-7 & $51,53,97,6$ & 807 & 10513,0 & 176 & 158.5 & 209 & $34 \quad 16,3$ \\
\hline
\end{tabular}

Os metais calcófilos encontram-se acima do limite de detecção da técnica utilizada em quase todos os pontos analisados. A distribuição desses elementos nos gossans não parece obedecer aos mesmos padrões de distribuição no minério fresco, onde eles se encontram concentrados nas áreas correspondentes aos seus sulfetos portadores. Nos plasmas goethíticos, $\mathrm{Pb}, \mathrm{Zn}$ e $\mathrm{Cu}$ distribuem-se aleatoriamente, havendo notável variação dos teores, mesmo entre pontos adjacentes (Tabs. 7, 8, 9). Na maior parte dos pontos analisados, no entanto, a ordem de abundância é a mesma constatada nas análises químicas totais: $\mathrm{Pb}>\mathrm{Zn}>\mathrm{Cu}$.

Extração de amorfos Oito amostras foram submetidas à dosagem de $\mathrm{Fe}, \mathrm{Pb}, \mathrm{Cu}$ e $\mathrm{Zn}$ após ataque total $(\mathrm{T})$ e parcial para extração de amorfos (O). Os resultados, apresentados na Tabela 10, mostram que uma pequena porcentagem do $\mathrm{Fe}$ total $(\mathrm{O} / \mathrm{T})$, variando entre $1,8 \mathrm{e}$ $15,8 \%$, encontra-se em estado amorfo. Esses dados confirmam a suposição da existência de fases ferrruginosas amorfas, já sugerida pelos valores excessivamente elevados da perda ao fogo nas análises químicas totais.

Uma parcela de $\mathrm{Pb}, \mathrm{Zn}$ e Cu é extraída juntamente com Fe amorfo. Em cada amostra, as porcentagens de amorfos $(\mathrm{O} / \mathrm{T})$ de $\mathrm{Pb}, \mathrm{Zn}$ e $\mathrm{Cu}$ são sistematicamente superiores às de Fe amorfo (Tab. 10). Considerando o conjunto de amostras, constata-se que a relação $\mathrm{O} / \mathrm{T}$ de $\mathrm{Fe}$ versus $\mathrm{O} / \mathrm{T}$ de $\mathrm{Pb}, \mathrm{Zn}$ e Cu é aproximadamente linear (Fig. 7). Esses dados indicam que uma fração dos elementos calcófilos está associada aos compostos amorfos de ferro. 

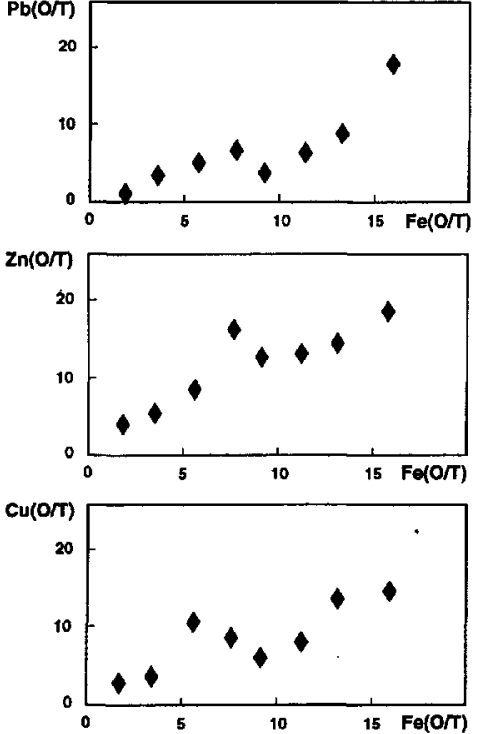

Figura 7 - Porcentagem de Fe amorfo $(\mathrm{O} / \mathrm{T})$ versus porcentagem de $\mathrm{Pb}, \mathrm{Zn}$ e $\mathrm{Cu}$ amorfos $(\mathrm{O} / \mathrm{T})$.

DISCUSSÃO DOS RESULTADOS E CONCLUSÕES OS

corpos de minério sulfetado enriquecidos em $\mathrm{Au}, \mathrm{Ag}, \mathrm{Pb}, \mathrm{Zn}$ e $\mathrm{Cu}$ do Alvo Cabeça Seca foram exumados quando da dissecação da Superfície Sul-Americana, no Terciário superior. A partir dessa época, suas extremidades aflorantes sofreram a ação do intemperismo sob clima tropical, levando à formação de um perfil capeado por gossan. Dada a generalizada interpenetração dos níveis sulfetados com o fílito encaixante, os gossans resultaram em materiais muito heterogêneos. Esses são formados por uma mistura, em proporções variadas, de um polo ferruginoso, essencialmente neoformado, composto pelos óxi-hidróxidos de ferro provenientes da alteração dos sulfetos, e um polo rochoso, composto predominantemente por quartzo e illita residuais.

Nos gossans do Alvo Cabeça Seca, os óxi-hidróxidos de ferro contendo $\mathrm{Au}, \mathrm{Ag}, \mathrm{Pb}, \mathrm{Zn}$ e $\mathrm{Cu}$ representam o produto final da alteração dos sulfetos. Não está, entretanto, excluída a existência, no perfil de alteração, de outros minerais que seriam os hospedeiros intermediários desses metais, entre sua liberação dos sulfetos primários e sua captura pelos óxi-hidróxidos de ferro, como é comum em perfis de alteração desse tipo (Blain \& Andrew 1977, Nickel 1984). Esses minerais poderiam estar presentes em horizontes mais profundos do perfil, os quais não foram expostos nas trincheiras, não tendo sido, portanto, amostrados.

Contrariamente ao que é comumente descrito na literatura (por exe mplo, em Lindgren 1933, Bateman 1942, Blanchard 1968, Andrew 1980) não foram encontradas, nas amostras estudadas, as texturas características de gossans desenvolvidos sobre mineraliza-ções de $\mathrm{Pb}$ $\mathrm{Zn}-\mathrm{Cu}$. O único sulfeto que deixa pseudomorfos caracterís-ticos, de forma cúbica, é a pirita. A ausência de texturas diagnosticas de outros sulfetos deve-se provavelmente à sua granulação mais fina, forma irregular e freqüente ocorrência como inclusões nos cristais de pirita. A principal fase portadora de $\mathrm{Fe}$ nos gossans é a goethita, mas esse elemento ocorre também, como oxido, sob forma de hematita e de compostos amorfos. Do ponto de vista geoquímico, os gossans apresentam uma assinatura característica, marcada por valores elevados de $\mathrm{Pb}$ e $\mathrm{Zn}$, moderados de $\mathrm{Cu}$ e teores interessantes de $\mathrm{Au}$ e Ag. Esses cinco elementos estão associados preferencialmente ao polo ferruginoso dos gossans, mas comportam-se como dois conjuntos de associações independentes: $\mathrm{Pb}, \mathrm{Zn}$ e $\mathrm{Cu}$, por um lado, e $\mathrm{Au}$ e $\mathrm{Ag}$, por outro. Essa característica é certamente herdada de uma feição primária do minério, no qual $\mathrm{Au}$ e $\mathrm{Ag}$ estão associados à pirita, mas não aos sulfetos de $\mathrm{Pb}$, $\mathrm{Zn}$ e Cu. Pode, no entanto, ter também uma contribuição do processo intempérico: $\mathrm{Pb}, \mathrm{Cu}$ e $\mathrm{Zn}$, muito mais solúveis que $\mathrm{Au}$ e $\mathrm{Ag}$ no meio supérgeno, migrariam a distâncias maiores, acentuando a separação entre os dois grupos.

As análises químicas pontuais mostraram que os óxi-hidróxidos de ferro contêm quantidades substanciais dos elementos calcófilos, que podem chegar até $1,6 \%$ de $\mathrm{PbO}, 0,5 \%$ de $\mathrm{ZnO}$ e $0,3 \%$ de $\mathrm{CuO}$. Esses valores são da ordem de grandeza dos encontrados nas análises pontuais em plasmas goethíticos dos gossans de Teutonic Bore-Austrália (Nickel 1984) e Irecê-BA (Oliveira et al. 1993). $\mathrm{Pb}, \mathrm{Zn}$ e $\mathrm{Cu}$ devem ter sido co-precipitados com os óxi-hidróxidos de ferro na época de sua formação, ou subseqüentemente adsorvidos. A distribuição desses elementos nos plasmas goethíticos é aleatória, não havendo concentração em determinados pontos, como seria de se esperar se precipitassem in situ, a partir de sua liberação dos sulfetos. Parece, portanto, que, uma vez desestabilizados seus sulfetos, esses elementos entram em solução e se movem, passando eventualmente por hospedeiros intermediários, antes de precipitar associados aos óxi-hidróxidos de ferro.

A extração química seletiva permitiu concluir que as fases cristalinas do ferro são predominantes nos gossans e que são elas, especialmente a goethita, que incorporam as maiores quantidades dos metais calcófilos. Resultados semelhantes foram encontrados por Fonseca \& Martin (1982) e Vairinho \& Fonseca (1989) em gossans da região do Alentejo (Portugal). No Alvo Cabeça Seca, no entanto, uma quantidade não negligenciável de Fe encontra-se amorfo, e a ela está associada uma fração importante do chumbo, zinco e cobre.

Os gossans apresentam teores de ouro bem superiores aos do minério primário, o que indica que a alteração supérgena promoveu a sua concentração. Dados sobre a morfologia e composição das partículas de ouro, o que será considerado em mais detalhe em outro artigo, mostram evidências da existência de ouro secundário. Isso leva a supor que, ao lado de um processo de concentração residual de ouro, também poderia teria havido concentração absoluta desse metal, por migração e precipitação em certos níveis dos gossans, a exemplo dos casos discutidos, entre outros, por Nickel \& Daniels (1989).

Agradecimentos Parte deste trabalho foi desenvolvida como dissertação de mestrado no Instituto de Geociências da USP pelo primeiro autor, sob orientação da segunda autora. Só foi possível realizá-lo porque contamos com a inestimável colaboração da MET AGO, através do geólogo Olavo Caramori Borges.

\section{Referências}

Andrew, R.L. 1980. Supergene alteration and gossan textures of base-metal ores in southern Africa. Minerals Sci. Engeneering 12:193-215.

Barbosa, O.; Braun, O.P.G.; Baptista, M.B.; Dyer, R.C.; Cotia, J.C. 1981. Projeto Brasilia, Brasília, Prospec/DNPM, 326p. (Relatório final).

Barbosa, P.A.R.; Borges, O.C.; Costa, H.F. da, Lacerda Neto, A.P. 1990. Prospccção de ouro no Grupo Canastra - exemplo de Luziânia-GO. In: SBG, Congr. Brás. Gcol., 41, Natal, Anais 3:1472-1486.

Bateman, M. 1942. Economic Mineral Deposits, New York, Wiley, 898p.

Blain, C.F.; Andrew, R.L. 1977. Sulphide weathering and evaluation of gossans in mineral exploration. Minerals Sci. Engeneering, 9(3): 119-150.

Blanchard, R. 1968. Interpretation of leached outcrops. Nevada Bur. Mines, Bull. 66, 196p.

Braun, O.P.G. 1971. Contribuição à geomorfologia do Brasil Central. Rev. Bras. Geografia, ano 32, 3:3-39

Cambier, P. 1986. Infrared study of goethite of varying crystallinity and particle size I. Interpretation of $\mathrm{OH}$ and lattice vibration frequencies. Clay Minerals, 21:191-200.

Fitzpatrick, R.W.; Schwertmann, U. 1982. Al-substituled goethite - an indicator of pcdogenic and weathering environment in South Africa. Geoderma, 27:335-347.

Fonseca, B.C.; Martin, H. 1982. Distribution des elements Pb, Zn et Fe dans la zone d'oxidation du gisement de Balsa-Portel (Alto Alentejo-Portugal) et determination des phases support $\mathrm{du} \mathrm{Pb}$ et du $\mathrm{Zn}$ par extraction selective sequenciclle. Bol. Soc. Geol. Portugal, XXIII:91-100.

Hagemann, S. 1989. The petrology and structural geology of the Proterozoic Canastra Group near Luziânia-Goiás, Brazil. Zbl. Geol. Palaont., I(5/6):887-901.

Lacerda Neto, P.L.; Mattos, S.C. 1990. Prospecção e pesquisa das mineralizações de ouro, prata e sulfetos de metais básicos do Alvo Cabeça Seca 9ACSO, Luziânia, sudeste de Goiás, METAGO, Goiânia, 56p. (Relatório inédito).
Lindgren, W. 1933. Mineral Deposits, 4 ed.. New York, McGraw Hill, 930p. differentiation of various classes of soils. Can. J. Soil Sci., 46:13-22.

Nickel, E.H. 1984. The mineralogy and geochemistry of the weathering profile of the Teutonic Bore Cu-Pb-Zn-Ag sulphide deposit. J. Geoch. Exploration, 22:239-264.

Nickel, E.H.; Daniels, J.L.I 989. Gossans. In K.H. Wolf (cd.) Handbook of stratabound and stratiform ore deposits. Amsterdam, Elscvicr, 261-390.

Oliveira, S.M.B. dc; Magat, P.; Blot, A. 1993. O gossan de Ircce-LapSo (BA). Geochim. Brasiliensis, 7(2): $m-149$

Schobbcnhaus, C.; Campos, D. dc A .; Der/e, G.R.; Asmus, H.E. 198 1. Mapa geológico do Brasil e da áera oceânica adjacente, incluindo depósitos minerais, Escala 1:2500000, DNPM, Brasília.

Schulze, D.G.; Schwertmann, U. 1987. The influence of aluminium on iron oxides: XII. Properties of goethites synthesiscd in $3 \mathrm{M} \mathrm{KOH}$ at $25^{\circ} \mathrm{C}$. Clay Minerals, 22:83-92.

Stubican, V; Roy, R. 1961 Isomorphous substitution and infra-red spectra of the layer lattice silicates. Am. Mineralogist, 46:32-51

Vairinho, M.M.; Fonseca, E.C. 1989. Distribuição do Fe, Mn, Zn, Pb e Cu na zona de oxidação supergénica do jazigo da Preguiça (Alto Alentejo, Portugal). Determinação das fases-suporte do $\mathrm{Zn}, \mathrm{Pb}$ e $\mathrm{Cu}$ por cxtracção química sclectiva sequncial. Rev. Un. Aveiro,
McKcaguc, J.A.; Day, J.H. 1966. Dithionitc and oxalatc cxtractable Fe and Al as aides in 